\title{
Frailty as a predictor of mortality among patients with COVID-19: a systematic review and meta-analysis
}

\author{
Xiao-Ming Zhang ${ }^{1}$, Jing Jiao ${ }^{1}$, Jing Cao ${ }^{1}$, Xiao-Peng Huo ${ }^{1}$, Chen Zhu' ${ }^{1}$ Xin-Juan $\mathrm{Wu}^{1 *}$ and Xiao-Hua Xie ${ }^{2^{*}}$
}

\begin{abstract}
Background: A large number of studies have explored the association between frailty and mortality among COVID19 patients, with inconsistent results. The aim of this meta-analysis was to synthesize the evidence on this issue.

Methods: Three databases, PubMed, Embase, and Cochrane Library, from inception to 20th January 2021 were searched for relevant literature. The Newcastle-Ottawa Scale (NOS) was used to assess quality bias, and STATA was employed to pool the effect size by a random effects model. Additionally, potential publication bias and sensitivity analyses were performed.

Results: Fifteen studies were included, with a total of 23,944 COVID-19 patients, for quantitative analysis. Overall, the pooled prevalence of frailty was 51\% (95\% Cl: 44-59\%). Patients with frailty who were infected with COVID-19 had an increased risk of mortality compared to those without frailty, and the pooled hazard ratio (HR) and odds ratio (OR) were 1.99 (95\% Cl: 1.66-2.38) and 2.48 (95\% Cl: 1.78-3.46), respectively. In addition, subgroup analysis based on population showed that the pooled ORs for hospitalized patients in eight studies and nursing home residents in two studies were 2.62 (95\% Cl: 1.68-4.07) and 2.09 (95\% Cl: 1.40-3.11), respectively. Subgroup analysis using the frailty assessment tool indicated that this association still existed when using the clinical frailty scale (CFS) (assessed in 6 studies, pooled $\mathrm{OR}=2.88,95 \% \mathrm{Cl}: 1.52-5.45$; assessed in 5 studies, pooled $\mathrm{HR}=1.99,95 \% \mathrm{Cl}$ : 1.662.38) and other frailty tools (assessed in 4 studies, pooled $\mathrm{OR}=1.98,95 \% \mathrm{Cl}: 1.81-2.16$ ). In addition, these significant positive associations still existed in the subgroup analysis based on study design and geographic region.

Conclusion: Our study indicates that frailty is an independent predictor of mortality among patients with COVID19. Thus, frailty could be a prognostic factor for clinicians to stratify high-risk groups and remind doctors and nurses to perform early screening and corresponding interventions urgently needed to reduce mortality rates in patients infected by SARS-CoV-2.
\end{abstract}

Keywords: Frailty, Mortality, COVID-19, Older adults, Meta-analysis

\footnotetext{
* Correspondence: wuxinjuan@sina.com; 13560779836@163.com

${ }^{1}$ Department of Nursing, Chinese Academy of Medical Sciences - Peking Union Medical College, Peking Union Medical College Hospital (Dongdan campus), Beijing 100730, China

${ }^{2}$ Shenzhen Second People's Hospital/the First Affiliated Hospital of Shenzhen University Health Science Center, Shenzhen 518000, China
}

(c) The Author(s). 2021 Open Access This article is licensed under a Creative Commons Attribution 4.0 International License, which permits use, sharing, adaptation, distribution and reproduction in any medium or format, as long as you give appropriate credit to the original author(s) and the source, provide a link to the Creative Commons licence, and indicate if changes were made. The images or other third party material in this article are included in the article's Creative Commons licence, unless indicated otherwise in a credit line to the material. If material is not included in the article's Creative Commons licence and your intended use is not permitted by statutory regulation or exceeds the permitted use, you will need to obtain permission directly from the copyright holder. To view a copy of this licence, visit http://creativecommons.org/licenses/by/4.0/ The Creative Commons Public Domain Dedication waiver (http://creativecommons.org/publicdomain/zero/1.0/) applies to the data made available in this article, unless otherwise stated in a credit line to the data. 


\section{Background}

A global pandemic of coronavirus disease 2019 (COVID19) was first reported in Wuhan city, China, in December 2019 [1]. The total number of confirmed cases was 96,877 , 399 worldwide on 23 January 2021 (https://www. worldometers.info/coronavirus/), with the highest mortality among older adults from different geographic regions, resulting in a huge burden for every sector of society, especially the global healthcare system. It has been reported that older adults living in community-dwelling or nursing homes are the most vulnerable group with the highest mortality rates for COVID-19 because of a variety of comorbidities and lower levels of immunologic function compared to younger adults [2]. Identifying the risk factors for predicting mortality among patients with COVID-19 is significant for clinicians.

Recently, many factors have been prognosticated for mortality, such as age [3], diabetes [4], hypertension, and obesity [5]. However, it has been reported that these somatic conditions cannot comprehensively predict worse outcomes for COVID-19 patients. Thus, new prognostic risk factors are required for identifying and stratifying patients.

Older adults are characterized by heterogeneity of health and vigor. Single aspects, such as chronological age and concurrent disease, cannot truly reflect overall health status. To solve this knowledge gap, frailty syndrome has been widely introduced in recent decades. Frailty is defined as a condition characterized by weakness, progressive declined physiologic function and diminished strength, leading to vulnerability and reduced resilience to stressors with an increased risk of adverse outcomes [6]. Frailty was confirmed to be a predictor of risk with worse outcomes, such as falls, mortality and lower quality of life in different populations [7]. Several studies have presented the association between frailty and morality in patients with COVID-19, the majority of which have shown a clear association between increasing frailty and worse outcomes [8-13]. Three small and underpowered studies showed no association [14-16]. Given recent articles exploring this association between frailty and mortality [17-23], we believe that there is an urgent need to summarize the evidence of this important issue. The objective of our study is to systematically review and quantify the results of the associations between frailty and mortality, which could provide evidencebased suggestions for clinicians.

\section{Methods}

This meta-analysis followed the guidelines of the Preferred Reporting Items for Systematic Reviews and MetaAnalyses Statemen. We have registered our protocol in the PROSPERO database (CRD42021235666).

\section{Search strategy}

Three databases - PubMed, Embase, and Cochrane Library - were independently searched by two authors (XPH, CZ) from database inception to 20th January 2021. We also used a combination of keywords and medical subject headings (MeSH). The search strategy was below frail" or frailty (MeSH) and ("COVID-19" OR "Coronavirus Infection" OR "Coronavirus Infection Disease 2019" OR Coronavirus*) and (mortality or death or survival). Additionally, we tried to find relevant studies from references and searched for gray studies using the Google search engine. The detailed search strategy for PubMed is shown in supplemental file 1.

\section{Inclusion and exclusion criteria}

All observational studies describing the associations between frailty and mortality in patients with COVID-19 were included. We excluded article types such as comments, reviews, conferences, correspondence, editorials, letters to the editor and case reports. In addition, the study presented the effect size of the association by using frailty score as a continuous variable.

\section{Study selection process}

Two authors blindly screened the literature with Endnote software (Clarivate Analytics,USA) after storing all of the relevant articles. The first step was to delete the duplications and then check the articles by title and abstract, finally identifying full texts that met the the of inclusion and exclusion criteria. When there was a disagreement, the third author participated in making a final decision.

\section{Data extraction}

Two authors (XMZ and XHX) independently extracted the variables from the articles that were included, including basic characteristics (author, county, publication year, average age, prevalence of males/females, sample size, setting, and effect measures), study design, prevalence of frailty, frailty assessment scale, outcomes, effect size for the association with frailty, detailed variables of each adjustment model and mortality. The third author confirmed the final version of the date when there seemed to be any argument.

\section{Quality assessment}

Two authors (XMZ and XHX) performed a quality bias assessment using the Newcastle-Ottawa Scale (NOS), which is widely applied for observational studies. The total score ranged from 0 to 9 points, and the higher the score, the higher the quality of the study. There are three categories for the level of quality: low (0-4), moderate (5-7) and high (>7). 


\section{Statistical analysis}

The effect size (HR and OR) of the association between frailty and mortality was extracted by two independent authors (JJ and JC) with Microsoft Excel and was analyzed using STATA. The heterogeneity between the different studies was presented as $I^{2}$ and was detected by Cochran's Q test. The standard for the category of heterogeneity was defined as $I^{2}>50 \%$ for significance and $I$ ${ }^{2}<50 \%$ for insignificance. A random model was used to calculate and separately pool the effect size of HR and OR with a $95 \%$ CI between frailty and mortality because of the use of different populations, study designs, and various frailty assessment scales. In addition, subgroup analysis was also performed based on population, geographical region, different adjustment models and frailty assessment scales. Publication bias and sensitivity analysis were conducted by funnel plots.

\section{Search results and study characteristics}

We found 391 relevant articles from three databases, PubMed (183), Embase (195), and Cochrane Library (13). After using Endnote software to delete duplications, 296 articles remained. At this stage, two authors checked the titles and abstracts to identify closely relevant studies, with 33 assessed for eligibility. Consequently, after checking the full texts, 15 studies were included for quantitative analysis in terms of the predefined inclusion criteria. Detailed information for the reasons for exclusion is presented in Fig. 1.

Fifteen studies quantified the relationship between frailty and mortality that included 23,944 patients with COVID-19(shown in Table 1). Overall, a majority of the included studies focused on older adults. The study design in seven studies was prospective cohort studies $[8,12,17-20,22]$, while the others were all retrospective cohort studies [11, 13, 15, 16, 21, 23-25]. There were a variety of countries, ranging from the U.S. to European countries, with 2 in the USA $[11,24]$, five in the UK $[8$, 13, 15, 19, 22], 1 in Turkey [18],1 in France [16], 1 in Switzerland [23], 2 in Spain [21, 25], 2 in Sweden [12, 20], and 1 in the UK and Italy [17]. Of these, 13 study settings were in the hospital $[8,11-13,15-20,22,23$, $25]$ and two were in a nursing home [21, 24]. The prevalence of frailty ranged from 11.00 to $79 \%$, and the pooled result was 51\% (95\% CI: 44-59\%) (Supplemental Fig. 1). The majority of outcomes were in-hospital mortality, with three studies reporting 30-day mortality and one

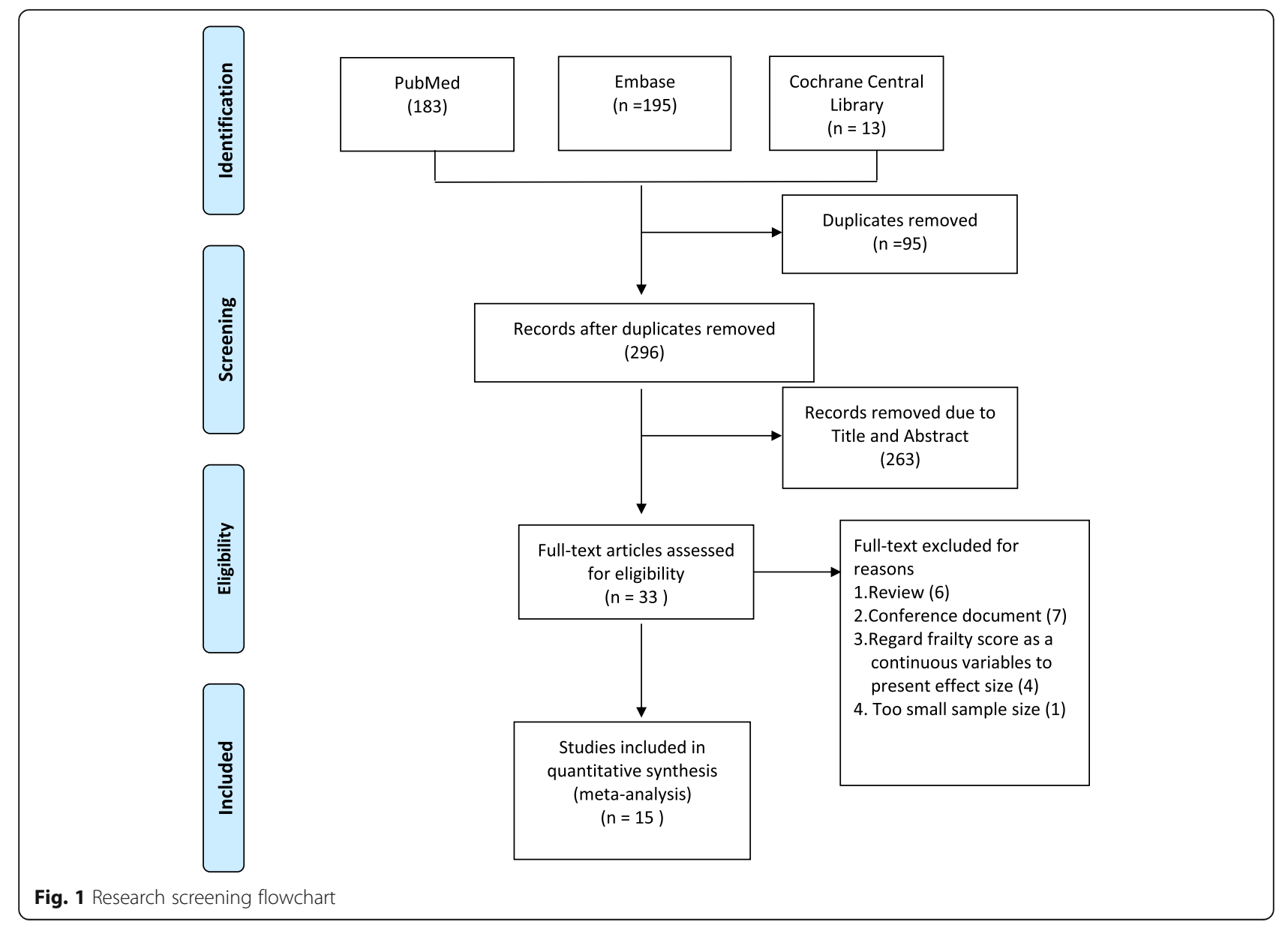




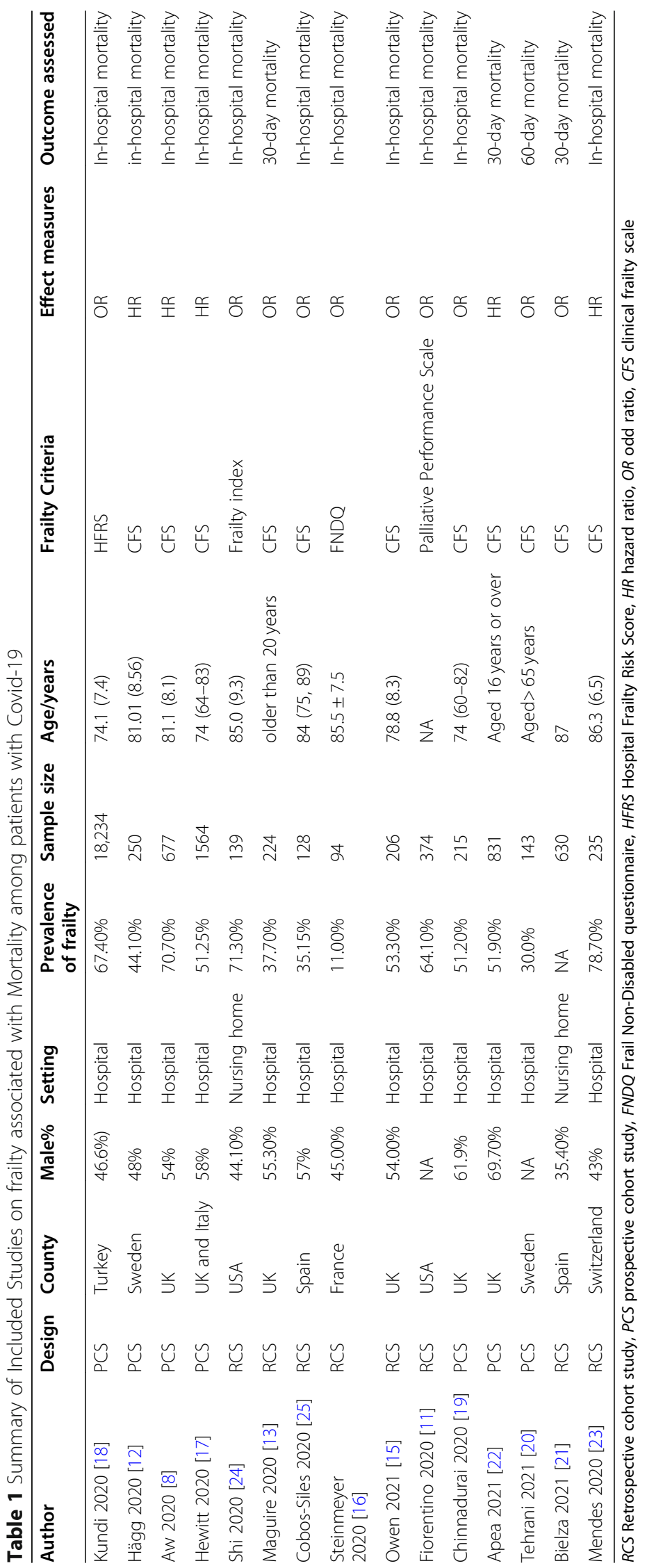


reporting 60-day mortality. The largest sample size was in Turkey [18], with 18,234 patients, and the smallest was in France [16], with 94 patients. Among all of the included studies, 11 studies used the clinical frailty scale (CFS) as an assessment tool for frailty [8, 12, 13, 15, 17, 19-23, 25], one used the hospital frailty risk score [18], one used the frailty index [24], one used the palliative performance scale [11] and one used the frail nondisabled questionnaire [16]. Detailed information of adjustment variables for each study was shown in Supplemental Table 1.

\section{Meta-analysis of the effects of frailty on mortality}

Fifteen studies were included in the meta-analysis. Ten studies considered OR as the result of the association between frailty and mortality. The pooled OR value was 2.48 (95\% CI: 1.78-3.46) among frail patients compared with COVID-19 patients without frailty. In addition, five studies used HR as an effect measure, with the pooled HR value of frail patients for mortality being 1.99 (95\% CI: 1.66-2.38), both of which indicate that frailty can be an independent predictor for mortality among patients with COVID-19 (Fig. 2).

\section{Subgroup analysis was based on different populations}

A majority of studies focused on hospitalized patients, with two studies reported among nursing home residents. Older nursing home residents infected with COVID-19 and with frailty had a 2.09-fold risk of morality compared to nonfrail patients (assessed in 2 studies, pooled OR $=2.09,95 \%$ CI: 1.40-3.11). Meanwhile, hospitalized patients also had similar results regardless of which effect measures were considered (assessed in 5 studies, pooled $\mathrm{HR}=1.99,95 \% \mathrm{CI}$ : $1.66-2.38$; assessed in 8 studies, pooled $\mathrm{OR}=2.62,95 \% \mathrm{CI}$ : 1.68-4.07) (Fig. 3).

\section{Subgroup analysis was based on different frailty assessment scales}

We performed a subgroup analysis of the frailty assessment tool by considering CFS versus other tools. The results showed that the pooled HR and OR of frailty among patients who died, compared to those without frailty, were 1.99 (95\% CI: 1.66-2.38) and 2.88 (95\% CI: 1.52-5.45), respectively, when using CFS in 11 studies. Other frailty assessment instruments in four studies included the frailty index, hospital frailty risk score, frail nondisabled questionnaire, and palliative performance scale, with a pooled OR of 1.98 (95\% CI: 1.81-2.16), as shown in Fig. 4.

\section{Subgroup analysis based on study design, geographic region, and different adjustment models}

Seven studies were prospective cohort studies, and the others were retrospective cohort studies; thus, we

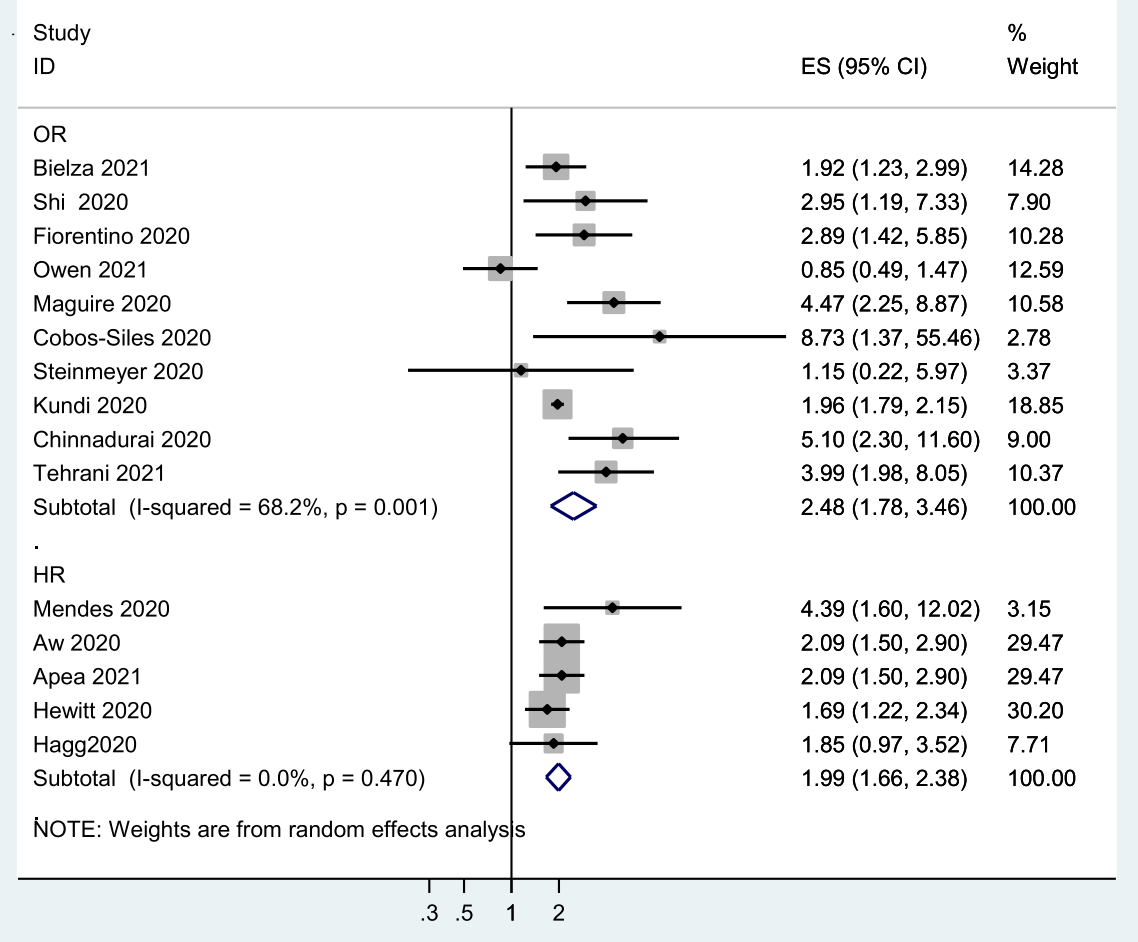

Fig. 2 Meta-analysis of the effects of frailty on mortality among patients with COVID-19 


\begin{tabular}{|c|c|c|c|}
\hline \multicolumn{2}{|l|}{ Study } & \multicolumn{2}{|r|}{$\%$} \\
\hline \multicolumn{2}{|l|}{ ID } & $\mathrm{ES}(95 \% \mathrm{Cl})$ & Weight \\
\hline \multicolumn{4}{|l|}{ Nursing home (OR) } \\
\hline Bielza 2021 & $\rightarrow$ & $1.92(1.23,2.99)$ & 80.73 \\
\hline Shi 2020 & - & $2.95(1.19,7.33)$ & 19.27 \\
\hline Subtotal $(I-$ squared $=0.0 \%, p=0.405)$ & & $2.09(1.40,3.11)$ & 100.00 \\
\hline \multicolumn{4}{|l|}{ Hospital (OR) } \\
\hline Fiorentino 2020 & & $2.89(1.42,5.85)$ & 13.63 \\
\hline Owen 2021 & & $0.85(0.49,1.47)$ & 15.83 \\
\hline Maguire 2020 & $\rightarrow$ & $4.47(2.25,8.87)$ & 13.93 \\
\hline Cobos-Siles 2020 & & $8.73(1.37,55.46)$ & 4.48 \\
\hline Steinmeyer 2020 & & $1.15(0.22,5.97)$ & 5.34 \\
\hline Kundi 2020 & - & $1.96(1.79,2.15)$ & 20.77 \\
\hline Chinnadurai 2020 & $\rightarrow$ & $5.10(2.30,11.60)$ & 12.31 \\
\hline Tehrani 2021 & 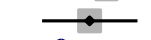 & $3.99(1.98,8.05)$ & 13.72 \\
\hline Subtotal $(I-$ squared $=74.6 \%, p=0.000)$ & & $2.62(1.68,4.07)$ & 100.00 \\
\hline \multicolumn{4}{|l|}{ Hospital (HR) } \\
\hline Mendes 2020 & & $4.39(1.60,12.02)$ & 3.15 \\
\hline Aw 2020 & $\rightarrow$ & $2.09(1.50,2.90)$ & 29.47 \\
\hline Apea 2021 & $\rightarrow$ & $2.09(1.50,2.90)$ & 29.47 \\
\hline Hewitt 2020 & $\rightarrow$ & $1.69(1.22,2.34)$ & 30.20 \\
\hline Hagg2020 & $\rightarrow$ & $1.85(0.97,3.52)$ & 7.71 \\
\hline Subtotal $(I-$ squared $=0.0 \%, p=0.470)$ & $\diamond$ & $1.99(1.66,2.38)$ & 100.00 \\
\hline \multicolumn{4}{|c|}{ NOTE: Weights are from random effects analysis } \\
\hline
\end{tabular}

Fig. 3 Meta-analysis of the effects of frailty on mortality based on different settings

performed a subgroup analysis based on study design. The results indicated a statistically significant association between frailty and mortality among cohort studies (assessed in 3 studies, pooled OR $=3.12$, 95\% CI: 1.60 6.09; assessed in 4 studies, pooled $\mathrm{HR}=1.94,95 \% \mathrm{CI}$ : 1.62-2.32). Similar results were shown in the retrospective cohort study (assessed in 7 studies, pooled $\mathrm{OR}=2.28$, 95\% CI: 1.34-3.88), as shown in Supplemental Fig. 2. We also performed a subgroup analysis based on geographic region due to the different prevalence levels of COVID-19 worldwide. The results found that the associations were higher in the USA (2 studies) than in European countries (13 studies), with both suggesting that patients with frailty have an incrementally greater risk of mortality than nonfrail COVID-19 patients (Supplemental Fig. 3). In addition, subgroup analysis based on the adjusted model showed that the association between frailty and mortality still existed in both models (5 unadjusted studies versus 10 adjusted studies) (Supplemental Fig. 4).

\section{Quality assessment}

A majority of studies had used more than a seven-point score, and one study had six points according to the criterion of the Newcastle-Ottawa Scale (Table 2).

\section{Sensitivity analysis and potential publication bias}

Begg's test was used to determine whether there was a publication bias, and the results showed no potential bias $(p=0.147)$ (Supplemental Fig. 5). We also conducted a leave-one-out sensitivity analysis, and the results indicated that our study was stable and robust (Supplemental Fig. 6).

\section{Discussion}

In this study, we found that COVID-19 patients with frailty have an increased risk of mortality than those without frailty, independent of study design, country, and setting, indicating that frailty could be a prognostic factor for clinicians to predict mortality and supporting the use of a frailty assessment to stratify high-risk hospitalized patients to provide appropriate medical care. This is the first meta-analysis with a large sample size, to the best of our knowledge, to explore the association between frailty and mortality among patients with COVID-19. Given the ongoing COVID-19 pandemic, the increasing number of deceased patients and the overwhelmed health care system, frailty screening could help clinicians establish a comprehensive prognostic tool for predicting mortality in patients with COVID-19 and early intervention for improving frailty syndrome to reduce mortality rates. 


Study
ID

Fig. 4 Meta-analysis of the effects of frailty on mortality based on different frailty assessment scales

A large number of studies pooled the prevalence of frailty among different populations that resided in nursing homes [26] or communities [27], with prevalences of 52.3\% (95\% CI: $37.9-66.5 \%)$ and $17.4 \%$ (95\% CI $14.4-$ $20.7 \%)$, respectively. Our study found that the prevalence of frailty in patients with COVID-19 was similar to that in nursing home residents, but for both groups, it was higher than that for community-dwelling older adults. This is not an exceptional finding because the median or average age in these included studies was more than 70 years old. Increasing age was a risk factor for increased prevalence of frailty [28]. The oldest people ( $>70$ years old) were reported to be the most vulnerable population for SARS-CoV-2 infection, especially older residents of nursing homes. In addition, different frailty assessment tools and comorbidities were also factors that produced variations in prevalence.

Frailty as a predictor of mortality has widely been applied in different populations: community-dwelling older adults [29], nursing home residents [30], critically ill patients [31] and oncology patients [32], with HR values ranging from 1.8 to 3.39 . A large number of evidencebased systematic reviews and meta-analyses found that frailty could be a predictive factor for adverse outcomes, including mortality [30], hospitalization [33], and readmission [34], which means that screening for frailty is very important in a clinical setting.

Although the mechanism between frailty and mortality has been described by previous studies, this association has not been completely explained because of the involvement of multiple complicated factors. Several reasons may account for this. First, compared to patients without frailty, patients with frailty suffer from a more vulnerable condition characterized by various observable deficits, such as a reduced physiologic reserve, chronic undernutrition and cognitive impairment, increasing the likelihood of an adverse outcome when patients are exposed to major negative stressors, including COVID-19 or surgery operations. Second, frailty involving the process of complex chronic inflammation and proinflammatory cytokines, such as C-reactive protein, tumor necrosis factor (TNF)-a, interleukin (IL) or interleukin-6, exacerbates the risk of mortality when patients contract COVID-19 [35]. A previous study reported that proinflammatory cytokines were enormously aggravated in patients with COVID-19 [36]. Proinflammatory cytokines related to frailty and COVID-19 cause an inflammatory storm in COVID-19 patients, progressing to the development of lung injury and later ARDS, intensifying the risk of mortality [14]. Third, older adults infected 


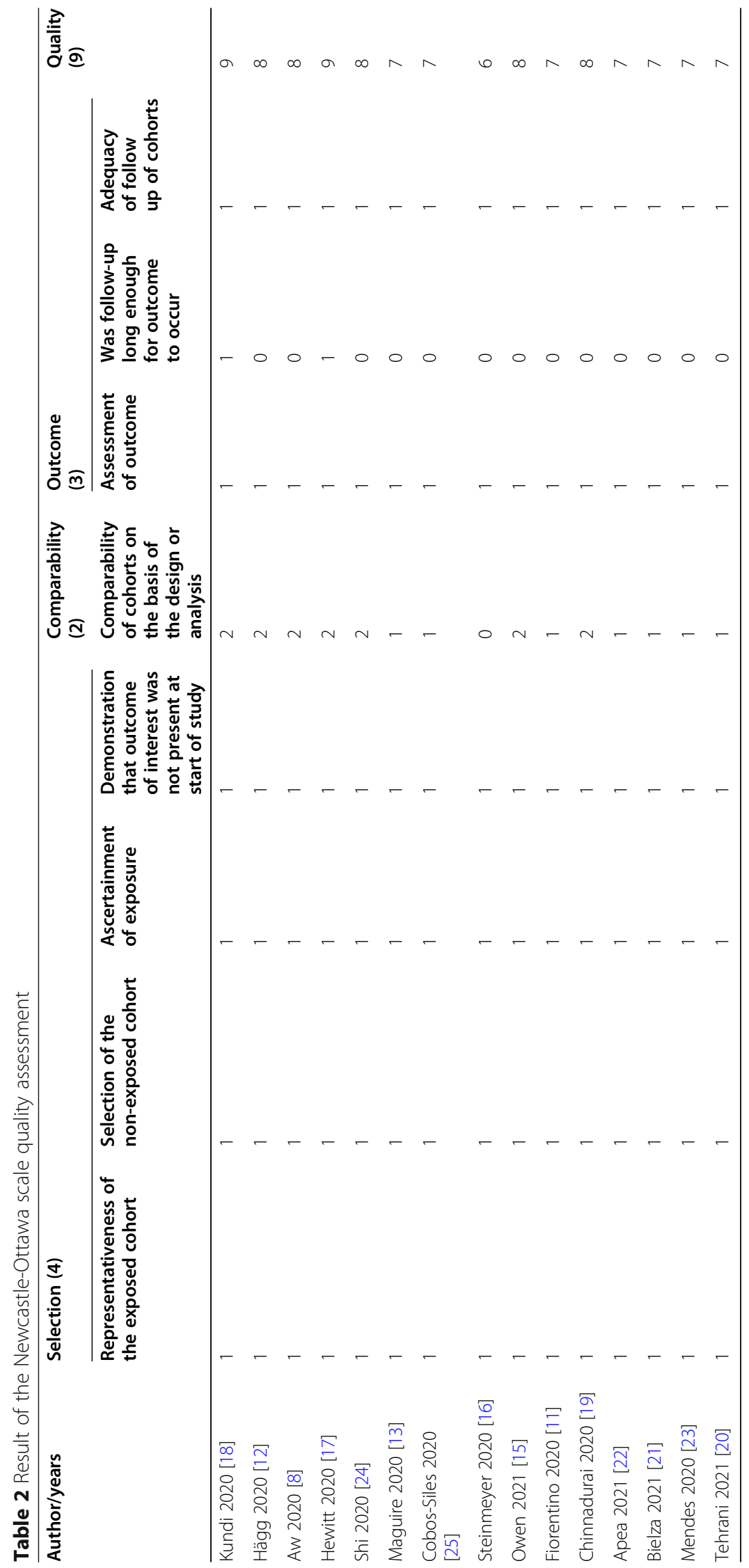


with SARS-CoV-2 have a high probability of developing severe status, requiring intensive medical care such as invasive ventilation, more drugs, and even extracorporeal circulation support. Frail older people are often unable to endure these invasive treatments or medical side effects, resulting in a greater likelihood of death during treatment. A previous meta-analysis showed that critically ill patients with frailty have a 1.71-fold risk of mortality. Thus, patients with both frailty and COVID-19 can develop a vicious cycle of impairment [31].

Our subgroup analysis, based on the frailty assessment tool, showed that frailty can be an independent predictor of mortality risk when using the clinical frailty scale and other frailty measurement tools. To date, several frailty measurement tools have been applied in different settings with various merits and demerits [37]. Optimal screening frailty scores should be practical, sensitive and available. Given the human-to-human transmission of COVID-19, being simple, less time-consuming, and accurate were the key points when clinicians considered using frailty instruments, especially for patients with a critical illness whose care requires more energy and time. CFS is considered the most common and efficient frailty assessment tool for a clinical setting because there are only five patient domains that need to be assessed [38]: basic ADLs, instrumental ADLs, chronic medical conditions that require drugs, exercise, and appearing fitter compared with patients of similar age. However, other tools need to be evaluated on many different aspects, such as the frailty index, which includes 35 items [39]. Previous studies have validated CFS as a predictor of adverse outcomes among hospitalized patients [40,41]. Additionally, our study also confirmed that frail patients assessed by CFS have an increased risk of morality compared to those without frailty. Recently, the National Institute for Clinical Excellence (NICE) published a guideline that recommends the CFS as an assessment tool to evaluate frailty in patients with COVID-19 [42]. Other subgroup analyses based on different designs and countries also showed similar results, meaning that the association between frailty and mortality in patients with COVID-19 is reliable and stable.

Our subgroup analysis shows that the association between frailty and mortality exists in different settings, both in hospitalized patients and nursing home residents. It is estimated that 2 in 5 US deaths from COVID-19 occurred in long-term care facilities or nursing homes. The main reason why nursing home residents are the most vulnerable group for COVID-19 is that older residents often suffer from multimorbidity, such as heart disease, diabetes, and kidney disease, overlapping with frailty, generating a vicious cycle, which was reported to be a risk of mortality [43, 44]. In fact, COVID-19 patients need to be treated at the designed hospital first in case of contacting other non-COVID-19 patients. Given the surging number of COVID-19 patients in the USA and Europe, hospitals are overwhelmed by COVID-19 patients, and medical staff are under great pressure. Government authorities and policymakers require most nursing home residents to remain in their facility. However, preventing COVID-19 transmission in nursing homes is very challenging but important.

Our systematic review and meta-analysis has some strengths and limitations. To the best of our knowledge, this is the first systematic review and meta-analysis study, which included 23,944 participants, to explore the association between frailty and mortality in patients with COVID-19 using comprehensive analysis methods. Our study may help answer the question of whether frailty could be a stratified tool for COVID-19 patients, and our results indicate that frailty is an independent predictor of mortality. However, there are also some limitations, and we need to remain cautious about the conclusions. First, two studies included nursing home residents, requiring more studies to confirm the impact of frailty on mortality in nursing home residents to guide policymakers to better manage this valued, high-risk group. Second, the numbers for some important frailty assessment tools, such as the frailty index or HFR, were limited, influencing the subgroup analysis results based on the frailty assessment tool. Five studies did not provide the adjusted model for the $\mathrm{HR}$ and $\mathrm{OR}$ values of frailty on mortality; therefore, the pooled $\mathrm{HR}$ and OR might be an overestimate. However, we performed a sensitivity analysis based on unadjustment and adjustment models and found that the association between frailty and mortality existed in both models. Third, we excluded some important studies that considered the frailty score as a continuous variable, which may have led some relevant information to be missed.

\section{Conclusion}

This systematic review and meta-analysis, which summarizes the evidence of the impact of frailty on mortality in COVID-19 patients, shows that COVID-19 patients with frailty have an increased risk of mortality compared with nonfrail patients with COVID-19, and this association is independent of geographic region, study design and setting. Overall, the assessment of frailty can help clinicians stratify the category risk of older patients with COVID-19 to help clinical healthcare workers manage and balance the benefits and risk for patients. Thus, multidimensional and effective medical care or intervention are required for this group, with the aim of reducing mortality rates.

\section{Abbreviations}

COVID-19: Coronavirus disease 2019; CFS: clinical frailty scale; NOS: Newcastle-Ottawa Scale; HR: hazard ratio; Cl: confidence interval; OR: odds ratio 


\section{Supplementary Information}

The online version contains supplementary material available at https://doi. org/10.1186/s12877-021-02138-5.

Additional file 1: Supplemental Figure 1. Pooled prevalence of frailty among patients with COVID-19.

Additional file 2: Supplemental Figure 2. Subgroup meta-analysis of the effects of frailty on mortality based on study design.

Additional file 3: Supplemental Figure 3. Subgroup meta-analysis of the effects of frailty on mortality based on geographic region.

Additional file 4: Supplemental Figure 4. Subgroup meta-analysis of the effects of frailty on mortality according to different models.

Additional file 5: Supplemental Figure 5. Begg's test for publication bias.

Additional file 6: Supplemental Figure 6. Sensitivity analysis of the association between frailty and mortality.

Additional file 7: Supplemental Table S1.

Additional file 8: Supplemental Table S2.

Additional file 9. Supplemental file 1.

\section{Acknowledgments}

The authors sincerely thank all staff of the Nursing Department of Peking Union Medical College. We also thank the staff of the Nursing Department of Shenzhen Second People's Hospital.

\section{Authors' contributions}

XJW and XHX were responsible for the concept and design. XMZ helped design the study and drafted the initial manuscript. JJ and JC conducted data acquisition. XPH and $\mathrm{CZ}$ were responsible for screening and selecting the articles. XMZ and XHX extracted all of the raw data and were responsible for assessing the quality of bias. All the authors have read and approved the manuscript.

\section{Funding}

This work was not supported by any funding.

\section{Availability of data and materials}

The datasets generated and/or analysed during the current study are available in the PubMed database.

\section{Declarations}

Ethics approval and consent to participate Not applicable.

\section{Consent for publication}

Approval was obtained from all the authors.

\section{Competing interests}

The author(s) declare no competing interests.

Received: 4 November 2020 Accepted: 8 March 2021

Published online: 17 March 2021

\section{References}

1. Zhu N, Zhang D, Wang W, Li X, Yang B, Song J, Zhao X, Huang B, Shi W, Lu R, Niu P, Zhan F, Ma X, Wang D, Xu W, Wu G, Gao GF, Tan W, China Novel Coronavirus Investigating and Research Team. A novel coronavirus from patients with pneumonia in China, 2019. N Engl J Med. 2020;382(8):727-33. https://doi.org/10.1056/NEJMoa2001017.

2. Zhou F, Yu T, Du R, Fan G, Liu Y, Liu Z, Xiang J, Wang Y, Song B, Gu X, et al. Clinical course and risk factors for mortality of adult inpatients with COVID19 in Wuhan, China: a retrospective cohort study. Lancet. 2020;395(10229): 1054-62.

3. Zhang S, Guo M, Duan L, Wu F, Hu G, Wang Z, Huang Q, Liao T, Xu J, Ma Y, et al. Development and validation of a risk factor-based system to predict short-term survival in adult hospitalized patients with COVID-19: a multicenter, retrospective, cohort study. Crit Care. 2020;24(1):438.

4. Varikasuvu SR, Dutt N, Thangappazham B, Varshney S. Diabetes and COVID19: a pooled analysis related to disease severity and mortality. Prim Care Diabetes. 2020.

5. Huang $Y$, Lu Y, Huang YM, Wang M, Ling W, Sui $Y$, Zhao HL. Obesity in patients with COVID-19: a systematic review and meta-analysis. Metab Clin Exp. 2020;113:154378. https://doi.org/10.1016/j.metabol.2020.154378.

6. Morley JE, Vellas B, van Kan GA, Anker SD, Bauer JM, Bernabei R, Cesari M, Chumlea WC, Doehner W, Evans J, et al. Frailty consensus: a call to action. J Am Med Dir Assoc. 2013;14(6):392-7. https://doi.org/10.1016/j.ja mda.2013.03.022.

7. Vermeiren S, Vella-Azzopardi R, Beckwée D, Habbig AK, Scafoglieri A, Jansen B, Bautmans I. Frailty and the Prediction of Negative Health Outcomes: A Meta-Analysis. J Am Med Dir Assoc. 2016:17(12):1163 e1161-1163.e1117.

8. Aw D, Woodrow L, Ogliari G, Harwood R. Association of frailty with mortality in older inpatients with Covid-19: a cohort study. Age Ageing 2020;49(6):915-22. https://doi.org/10.1093/ageing/afaa184.

9. Cobos-Siles M, Cubero-Morais P, Arroyo-Jiménez I, Rey-Hernández M, Hernández-Gómez L, Vargas-Parra DJ, González-Fernández M, CazorlaGonzález M, Gabella-Martín M, Ruíz-Albi T, Berezo-García JA, García-CrucesMéndez JF, Miramontes-González JP, Corral-Gudino L. Cause-specific death in hospitalized individuals infected with SARS-CoV-2: more than just acute respiratory failure or thromboembolic events. Intern Emerg Med. 2020;15(8): 1533-44. https://doi.org/10.1007/s11739-020-02485-y.

10. De Smet $R$, Mellaerts $B$, Vandewinckele H, Lybeert P, Frans E, Ombelet $S$, Lemahieu W, Symons R, Ho E, Frans J, et al. Frailty and Mortality in Hospitalized Older Adults With COVID-19: Retrospective Observational Study. J Am Med Dir Assoc. 2020;21(7):928-32 e921.

11. Fiorentino M, Pentakota SR, Mosenthal AC, Glass NE. The palliative performance scale predicts mortality in hospitalized patients with COVID-19. Palliat Med. 2020;34(9):1228-34. https://doi.org/10.1177/0269216320940566.

12. Hägg S, Jylhävä J, Wang Y, Xu H, Metzner C, Annetorp M, Garcia-Ptacek S, Khedri M, Boström AM, Kadir A, et al. Age, Frailty, and Comorbidity as Prognostic Factors for Short-Term Outcomes in Patients With Coronavirus Disease 2019 in Geriatric Care. J Am Med Dir Assoc. 2020;21(11):1555-9. e1552. https://doi.org/10.1016/j.jamda.2020.08.014.

13. Maguire D, Woods M, Richards C, Dolan R, Veitch JW, Sim WMJ, Kemmett OEH, Milton DC, Randall SLW, Bui LD, Goldmann N, Cameron A, Laird B, Talwar D, Godber I, Davidson A, McMillan DC. Prognostic factors in patients admitted to an urban teaching hospital with COVID-19 infection. J Transl Med. 2020;18(1):354. https://doi.org/10.1186/s12967-020-02524-4.

14. Miles A, Webb TE, McLoughlin BC, Mannan I, Rather A, Knopp P, Davis D. Outcomes from COVID-19 across the range of frailty: excess mortality in fitter older people. Eur Geriatric Med. 2020;11(5):851-5. https://doi.org/10.1 007/s41999-020-00354-7.

15. Owen RK, Conroy SP, Taub N, et al. Comparing associations between frailty and mortality in hospitalised older adults with or without COVID-19 infection: a retrospective observational study using electronic health records. Age Ageing. 2021;50(2):307-16.

16. Steinmeyer Z, Vienne-Noyes S, Bernard M, Steinmeyer A, Balardy L, Piau A, Sourdet S. Acute Care of Older Patients with COVID-19: Clinical Characteristics and Outcomes. Geriatrics (Basel, Switzerland). 2020;5(4):65.

17. Hewitt J, Carter B, Vilches-Moraga A, Quinn TJ, Braude P, Verduri A, Pearce L, Stechman M, Short R, Price A, Collins JT, Bruce E, Einarsson A, Rickard F, Mitchell E, Holloway M, Hesford J, Barlow-Pay F, Clini E, Myint PK, Moug SJ, McCarthy K, Davey C, Jones S, Lunstone K, Cavenagh A, Silver C, Telford T, Simmons R, Mutasem TEJ, Singh S, Paxton D, Harris W, Galbraith N, Bhatti E, Edwards J, Duffy S, Bisset C, Alexander R, Garcia M, Sangani S, Kneen T, Lee T, McGovern A, Guaraldi G. The effect of frailty on survival in patients with COVID19 (COPE): a multicentre, European, observational cohort study. Lancet Public Health. 2020;5(8):e444-51. https:/doi.org/10.1016/\$2468-2667(20)30146-8.

18. Kundi H, Çetin E, Canpolat U, Aras S, Celik O, Ata N, Birinci S, Çay S, Özeke Ö, Tanboğa IH, et al. The role of frailty on adverse outcomes among older patients with COVID-19. J Infect. 2020;81(6):944-51. https://doi.org/10.1016/j. jinf.2020.09.029.

19. Chinnadurai R, Ogedengbe O, Agarwal P, Money-Coomes S, Abdurrahman AZ, Mohammed S, Kalra PA, Rothwell N, Pradhan S. Older age and frailty are the chief predictors of mortality in COVID-19 patients admitted to an acute medical unit in a secondary care setting- a cohort study. BMC Geriatr. 2020; 20(1):409. https://doi.org/10.1186/s12877-020-01803-5. 
20. Tehrani S, Killander A, Åstrand P, Jakobsson J, Gille-Johnson P. Risk factors for death in adult COVD-19 patients: frailty predicts fatal outcome in older patients. Int J Infect Dis. 2021;102:415-21. https://doi.org/10.1016/j.jij.2020.10.071.

21. Bielza R, Sanz J, Zambrana F, Arias E, Malmierca E, Portillo L, Thuissard IJ, Lung A, Neira M, Moral M et al. Clinical Characteristics, Frailty, and Mortality of Residents With COVID-19 in Nursing Homes of a Region of Madrid. J Am Med Dir Assoc. 2021;22(2):245-52.e242.

22. Apea VJ, Wan YI, Dhairyawan R, Puthucheary ZA, Pearse RM, Orkin CM, Prowle JR. Ethnicity and outcomes in patients hospitalised with COVID-19 infection in East London: an observational cohort study. BMJ Open. 2021; 11(1):e042140. https://doi.org/10.1136/bmjopen-2020-042140.

23. Mendes A, Serratrice $C$, Herrmann FR, Genton L, Périvier S, Scheffler M, Fassier T, Huber P, Jacques MC, Prendki V, et al. Predictors of In-Hospital Mortality in Older Patients With COVID-19: The COVIDAge Study. J Am Med Dir Assoc. 2020;21(11):1546-54 e1543.

24. Shi SM, Bakaev I, Chen H, Travison TG, Berry SD: Risk Factors, Presentation, and Course of Coronavirus Disease 2019 in a Large, Academic Long-Term Care Facility. J Am Med Dir Assoc 2020, 21(10):1378-1383.e1371.

25. Cobos-Siles M, Cubero-Morais P, Arroyo-Jiménez I, Rey-Hernández M, Hernández-Gómez L, Vargas-Parra DJ, González-Fernández M, CazorlaGonzález M, Gabella-Martín M, Ruíz-Albi T et al. Cause-specific death in hospitalized individuals infected with SARS-CoV-2: more than just acute respiratory failure or thromboembolic events. Intern Emerg Med. 2020; 15(8):1533-44

26. Kojima G. Prevalence of frailty in nursing homes: a systematic review and meta-analysis. J Am Med Dir Assoc. 2015;16(11):940-5. https://doi.org/10.101 6/j.jamda.2015.06.025.

27. Siriwardhana DD, Hardoon S, Rait G, Weerasinghe MC, Walters KR. Prevalence of frailty and prefrailty among community-dwelling older adults in low-income and middle-income countries: a systematic review and metaanalysis. BMJ Open. 2018;8(3):e018195. https://doi.org/10.1136/bmjopen-201 7-018195.

28. Fhon JRS, Rodrigues RAP, Santos JLF, Diniz MA, Santos EBD, Almeida VC, Giacomini SBL. Factors associated with frailty in older adults: a longitudinal study. Rev Saude Publica. 2018;52:74. https://doi.org/10.11606/S1518-8787.2 018052000497.

29. Kojima G. Frailty defined by FRAlL scale as a predictor of mortality: a systematic review and meta-analysis. J Am Med Dir Assoc. 2018;19(6):480-3. https://doi.org/10.1016/j.jamda.2018.04.006.

30. Zhang X, Dou Q, Zhang W, Wang C, Xie X, Yang Y, Zeng Y. Frailty as a Predictor of All-Cause Mortality Among Older Nursing Home Residents: A Systematic Review and Meta-analysis. J Am Med Dir Assoc. 2019;20(6):65763 e654.

31. Muscedere J, Waters B, Varambally A, Bagshaw SM, Boyd JG, Maslove D, Sibley S, Rockwood K. The impact of frailty on intensive care unit outcomes: a systematic review and meta-analysis. Intensive Care Med. 2017;43(8):110522. https://doi.org/10.1007/s00134-017-4867-0.

32. Boakye D, Rillmann B, Walter V, Jansen L, Hoffmeister M, Brenner H. Impact of comorbidity and frailty on prognosis in colorectal cancer patients: a systematic review and meta-analysis. Cancer Treat Rev. 2018;64:30-9. https://doi.org/10.1016/j.ctrv.2018.02.003.

33. Chang SF, Lin HC, Cheng CL. The relationship of frailty and hospitalization among older people: evidence from a meta-analysis. J Nurs Scholarsh. 2018; 50(4):383-91. https://doi.org/10.1111/jnu.12397.

34. Zhao F, Tang $B$, Hu C, Wang B, Wang $Y$, Zhang $L$. The impact of frailty on posttraumatic outcomes in older trauma patients: a systematic review and meta-analysis. J Trauma Acute Care Surg. 2020;88(4):546-54. https://doi. org/10.1097/TA.0000000000002583.

35. Soysal P, Stubbs B, Lucato P, Luchini C, Solmi M, Peluso R, Sergi G, Isik AT, Manzato E, Maggi S, Maggio M, Prina AM, Cosco TD, Wu YT, Veronese N. Inflammation and frailty in the elderly: a systematic review and meta-analysis. Ageing Res Rev. 2016;31:1-8. https://doi.org/10.1016/j.arr.2016.08.006.

36. Fara A, Mitrev Z, Rosalia RA, Assas BM. Cytokine storm and COVID-19: a chronicle of pro-inflammatory cytokines. Open Biol. 2020;10(9):200160. https://doi.org/10.1098/rsob.200160.

37. Dent $E$, Kowal $P$, Hoogendijk EO. Frailty measurement in research and clinical practice: a review. Eur J Intern Med. 2016;31:3-10. https://doi.org/1 0.1016/j.ejim.2016.03.007.

38. Juma S, Taabazuing MM, Montero-Odasso M. Clinical frailty scale in an acute medicine unit: a simple tool that predicts length of stay. Can Geriatrics J. 2016;19(2):34-9. https://doi.org/10.5770/cgj.19.196.
39. Searle SD, Mitnitski A, Gahbauer EA, Gill TM, Rockwood K. A standard procedure for creating a frailty index. BMC Geriatr. 2008;8(1):24. https://doi. org/10.1186/1471-2318-8-24.

40. Basic D, Shanley C. Frailty in an older inpatient population: using the clinical frailty scale to predict patient outcomes. J Aging Health. 2015;27(4):670-85. https://doi.org/10.1177/0898264314558202.

41. Wallis SJ, Wall J, Biram RW, Romero-Ortuno R. Association of the clinical frailty scale with hospital outcomes. QJM. 2015;108(12):943-9. https://doi. org/10.1093/qjmed/hcv066.

42. Rockwood K, Song X, MacKnight C, Bergman H, Hogan DB, McDowell I, Mitnitski A. A global clinical measure of fitness and frailty in elderly people. Cmaj. 2005;173(5):489-95. https://doi.org/10.1503/cmaj.050051.

43. Duffy RE, Mattson BJ, Zack M. Comorbidities among Ohio's nursing home residents with diabetes. J Am Med Dir Assoc. 2005;6(6):383-9. https://doi. org/10.1016/j.jamda.2005.04.009.

44. Onder G, Cesari M, Maggio M, Palmer K. Defining a care pathway for patients with multimorbidity or frailty. Eur J Intern Med. 2017;38:1-2. https:// doi.org/10.1016/j.ejim.2017.01.013.

\section{Publisher's Note}

Springer Nature remains neutral with regard to jurisdictional claims in published maps and institutional affiliations.

\section{Ready to submit your research? Choose BMC and benefit from:}

- fast, convenient online submission

- thorough peer review by experienced researchers in your field

- rapid publication on acceptance

- support for research data, including large and complex data types

- gold Open Access which fosters wider collaboration and increased citations

- maximum visibility for your research: over $100 \mathrm{M}$ website views per year

At BMC, research is always in progress.

Learn more biomedcentral.com/submissions 